\title{
Diagnosis and management of asthma in preschoolers: A Canadian Thoracic Society and Canadian Paediatric Society position paper
}

\author{
Francine M Ducharme MD MSc${ }^{1}$, Sharon D Dell MD², Dhenuka Radhakrishnan MD MSc ${ }^{3}$, \\ Roland M Grad MDCM MSc FCFP ${ }^{4}$, Wade TA Watson MD MEd ${ }^{5}$, Connie L Yang MD MSc ${ }^{6}$, Mitchell Zelman MDCM ${ }^{7}$
}

\begin{abstract}
FM Ducharme, SD Dell, D Radhakrishnan, et al. Diagnosis and management of asthma in preschoolers: A Canadian Thoracic Society and Canadian Paediatric Society position paper. Can Respir J 2015;22(3):135-143.
\end{abstract}

Asthma often starts before six years of age. However, there remains uncertainty as to when and how a preschool-age child with symptoms suggestive of asthma can be diagnosed with this condition. This delays treatment and contributes to both short- and long-term morbidity. Members of the Canadian Thoracic Society Asthma Clinical Assembly partnered with the Canadian Paediatric Society to develop a joint working group with the mandate to develop a position paper on the diagnosis and management of asthma in preschoolers.

In the absence of lung function tests, the diagnosis of asthma should be considered in children one to five years of age with frequent ( $\geq 8$ days/month) asthma-like symptoms or recurrent $(\geq 2)$ exacerbations (episodes with asthma-like signs). The diagnosis requires the objective document of signs or convincing parent-reported symptoms of airflow obstruction (improvement in these signs or symptoms with asthma therapy), and no clinical suspicion of an alternative diagnosis. The characteristic feature of airflow obstruction is wheezing, commonly accompanied by difficulty breathing and cough. Reversibility with asthma medications is defined as direct observation of improvement with short-acting $\beta_{2}$-agonists (SABA) (with or without oral corticosteroids) by a trained health care practitioner during an acute exacerbation (preferred method). However, in children with no wheezing (or other signs of airflow obstruction) on presentation, reversibility may be determined by convincing parental report of a symptomatic response to a three-month therapeutic trial of a medium dose of inhaled corticosteroids with as-needed SABA (alternative method), or as-needed SABA alone (weaker alternative method). The authors provide key messages regarding in whom to consider the diagnosis, terms to be abandoned, when to refer to an asthma specialist and the initial management strategy. Finally, dissemination plans and priority areas for research are identified.

Key Words: Asthma; Child; Criteria; Diagnosis; Disease management; Preschool; Therapeutic trial

\section{POSITION STATEMENT DEVELOPMENT PROCESS}

A joint working group was formed with the mandate to develop a position paper on the diagnosis and management of asthma in preschoolers. The group included academic and community-based pediatricians, pediatric respirologists, a pediatric allergist and a family physician with combined expertise in pediatric acute and chronic asthma care, as well as knowledge translation.

The document was developed in accordance with Canadian Thoracic Society (CTS) requirements for a position paper. A scientific

\begin{abstract}
Le diagnostic et la prise en charge de l'asthme chez les enfants d'âge préscolaire : document de principes de la Société canadienne de thoracologie et de la Société canadienne de pédiatrie
\end{abstract}

L'asthme fait souvent son apparition avant l'âge de six ans. Cependant, ill subsiste des incertitudes relativement à quand et comment un enfant d'âge préscolaire ayant des symptômes de type asthmatique peut être diagnostiqué avec cette condition. Ceci retarde le traitement et contribue à la morbidité à court et à long terme. L'Assemblée clinique sur l'asthme de la Société canadienne de thoracologie s'est associée à la Société canadienne de pédiatrie pour créer un groupe de travail conjoint afin de préparer un document de principes sur le diagnostic et la prise en charge de l'asthme chez les enfants d'âge préscolaire.

En l'absence de mesures de la fonction pulmonaire, le diagnostic d'asthme devrait être envisagé chez les enfants de un à cinq ans ayant des symptômes de type asthmatique fréquents ( $\geq 8$ jours/mois) ou des exacerbations récurrentes $(\geq 2)$ (épisodes accompagnés de signes compatibles). Le diagnostic nécessite une documentation objective des signes cliniques ou un compte rendu parental convaincant de symptômes d'obstruction des voies respiratoires et de réversibilité de l' obstruction (amélioration suite à un traitement pour l'asthme), ainsi que l'absence de suspicion clinique de tout autre diagnostic. La respiration sifflante, souvent accompagnée de difficultés respiratoires et de toux, est le signe cardinal de l'obstruction des voies respiratoires. La réversibilité à la suite de la prise de médicaments pour l'asthme se définie par l'observation directe par un professionnel de la santé compétent, d'une amélioration après l'administration de $\beta_{2}$-agonistes à courte durée d'action (BACA) (accompagnés ou non de corticostéroïdes par voie orale) pendant une exacerbation aigue (méthode diagnostique privilégiée). Cependant, chez les enfants qui n'ont pas à l'examen une respiration sifflante (ni d'autres signes d'obstruction des voies respiratoires), la réversibilité peut être déterminée par un compte rendu parental convaincant d'une réponse symptomatique à un essai thérapeutique de trois mois de corticostéroïdes inhalés, à dose moyenne, avec un BACA au besoin (méthode diagnostique alternative), ou avec seulement un BACA au besoin (méthode diagnostique alternative moins certaine) est recommandé. Les auteurs présentent des messages clés quant aux enfants chez lesquels on doit envisager le diagnostic, quant aux termes désuets à abandonner, quant aux situations pour lesquelles on doit orienter l'enfant vers un spécialiste de l'asthme et quant à la stratégie de prise en charge initiale. Enfin, ils décrivent la stratégie de diffusion de ces messages et identifient les domaines de recherche prioritaires.

literature review was conducted and key messages were agreed on by unanimous consensus through extensive discussions based on review of the evidence and existing guidelines. The completed document was subsequently sent for external review to four experts, as well as the CTS Canadian Respiratory Guidelines Committee, and the Canadian Pediatric Society Community Paediatrics Committee and Respiratory Health Section Executive. The final document was then approved for publication by the CTS Executive and the Canadian Paediatric Society Board of Directors.

${ }^{1}$ Departments of Pediatrics and of Social and Preventive Medicine, Centre Hospitalier Universitaire Sainte-Justine, University of Montreal, Montreal,

Quebec; ${ }^{2}$ Department of Pediatrics and IHPME, The Hospital for Sick Children, University of Toronto, Toronto; ${ }^{3}$ Department of Pediatrics,

Children's Hospital, London Health Sciences, Western University, London, Ontario; ${ }^{4}$ Department of Family Medicine, Jewish General Hospital,

McGill University, Montreal, Quebec; ${ }^{5}$ Department of Pediatrics, IWK Health Centre, Dalhousie University, Halifax, Nova Scotia; ${ }^{6}$ Department of

Pediatrics, British Columbia Children's Hospital, University of British Columbia, Vancouver, British Columbia; 7 Department of Pediatrics, Queen

Elizabeth Hospital, Charlottetown, Prince Edward Island, Dalhousie University, Halifax, Nova Scotia

Correspondence and reprints: Dr Francine M Ducharme, Canadian Thoracic Society, Lung Association - National Office, 300-1750 Courtwood

Crescent, Ottawa, Ontario K2C 2B5. Telephone 613-569-6411, fax 613-569-8860, e-mail ctsinfo@lung.ca 


\section{PREAMBLE}

Uncertainty exists as to how and when a preschool-age child with symptoms suggestive of asthma can be diagnosed with the condition. The wide spectrum of labels commonly used in preschoolers, denoting either a suggestive pathophysiology (eg, 'bronchospasm' or 'reactive airway disease'), symptoms (eg, 'wheeze' or 'chronic cough'), vague diagnoses ('wheezy bronchitis' or 'happy wheezer') or, possibly, inappropriate diagnoses (eg, repeated 'bronchiolitis' or 'recurrent bronchitis or pneumonia') (1), attests to the need for clarity.

In school-age children and adults, guidelines recommend the use of lung function tests, primarily spirometry, to confirm the diagnosis $(2,3)$. In children $<6$ years of age, the forced expiratory manoeuvre required for spirometry is difficult to perform, and alternative lung function tests for preschoolers are limited to a few pediatric academic settings or are insufficiently specific. Consequently, there is controversy as to when the diagnostic label of 'asthma' should be applied to preschool-age children. Some experts prefer reserving the diagnosis of asthma for children with persistent or atopic symptoms and refer to those who have asthma symptoms only with upper respiratory tract infections (URTIs) as having 'viral-induced wheezing' (4). Other specialists recommend considering children with either pattern of asthma symptoms as having asthma.

Given these issues, we offer a pragmatic approach to confirm the diagnosis of asthma in children one to five years of age, and refer readers to the 2012 CTS guideline update (2) for the management of children $\geq 6$ years of age. The target audience for the present position statement includes family physicians, pediatricians, respirologists, allergists, emergency physicians and other health care practitioners.

Three main approaches have historically been proposed to make a presumptive diagnosis of asthma in preschoolers: a list of suggestive symptoms; the exclusion of alternative diagnoses; and a set of features that predict asthma at six years of age (ie, when old enough to perform spirometry). Lists of nonprioritized criteria, with an unspecified number required for the diagnosis, have led to implementation difficulties. Exclusion of alternative conditions, resulting in unnecessary testing and parental anxiety, has reassured physicians on the absence of comorbidities without confirming the diagnosis of asthma. Several features are associated with the persistence of asthma at school age, such as the number of wheezing episodes and personal or family history of atopy (as identified in the Asthma Predictive Index [5]), or the age of onset and trajectory of symptoms over time (6); these criteria have slowly become synonymous with the diagnosis of asthma in toddlers, even if this was not the original intention. Moreover, the prediction tools are far from perfect $(7,8)$ and a future trajectory of symptoms cannot be used to make a diagnosis at any age.

Most children with asthma experience onset of symptoms in the preschool years. Preschoolers have the highest rate of emergency department visits and hospital admissions for asthma symptoms, compared with other age groups $(9,10)$. Wheezing in early life has been associated with reduced lung function at six years of age that generally persists until adulthood (11); the magnitude of the reduction is approximately a $10 \%$ lower predicted forced expiratory volume in $1 \mathrm{~s}$ $\left(\mathrm{FEV}_{1}\right)$, compared with healthy peers (11). Airway remodelling (ie, irreversible damage to the airways) has been documented in toddlers and may explain the altered lung function trajectory (12). Although up to $60 \%$ of children become asymptomatic by six years of age, preschool wheeze is frequently associated with persistence until, or recurrence in, adulthood (6). Importantly, evidence indicates that recurrent preschool wheezing responds to inhaled corticosteroid (ICS) therapy, similar to older children and adults (13). Early diagnosis is, therefore, important to avoid treatment delay, reduce morbidity and, potentially, maximize lung growth and function. Our proposed operational criteria aim to standardize the diagnosis of asthma in the absence of lung function tests. As with all clinical diagnostic approaches, there is a risk for misclassification. We acknowledge that these diagnostic criteria may lead to a slight overdiagnosis of asthma, which, in our view, outweighs the greater negative impact of underdiagnosis.

\section{KEY MESSAGES}

1. Terms such as 'bronchospasm', 'reactive airway disease', 'wheezy bronchitis' and 'happy wheezer' should be abandoned.

2. Recurrent preschool wheezing can be associated with substantial morbidity and may impact long-term health.

\section{KEY CRITERIA FOR THE DIAGNOSIS OF ASTHMA IN PRESCHOOLERS}

Asthma is an inflammatory disorder of the airways characterized by episodic or persistent symptoms such as dyspnea, chest tightness, wheezing, sputum production and cough, associated with variable airflow limitation and airway hyper-responsiveness to endogenous or exogenous stimuli (2). These features, well documented in school-age children and adults, are presumed to also apply to preschoolers. We propose that the diagnosis of asthma in preschoolers - in whom spirometry cannot be readily measured - requires the objective documentation of signs (or convincingly reported symptoms) of airflow obstruction and reversibility of airflow obstruction (ie, improvement of signs and symptoms with asthma medication), in the absence of clinical factors suggestive of an alternative diagnosis (Table 1). Personal atopy (eg, eczema, food allergy, etc) and family history of asthma heighten the suspicion of, but are not necessary for, the diagnosis. These diagnostic criteria apply to children with recurrent $(\geq 2)$ asthma-like symptoms or exacerbations (episodes with asthma-like signs), even when only triggered by viral respiratory infections.

\section{Airflow obstruction}

Wheezing is the most specific sign of airflow obstruction. Occurring predominantly during expiration, with increasing airflow obstruction, wheezing can be heard during inspiration until it becomes absent with severely diminished airflow. It is most reliably documented by a trained health care practitioner using a stethoscope (preferred diagnostic method), but can be audible without a stethoscope. When parents report 'wheezing', it is important to verify what is meant because the term is often used nonspecifically to describe nasal or otherwise noisy or troubled breathing sounds unrelated to asthma (14) (alternative dignostic method).

Other less-specific signs of airflow obstruction are often associated with wheezing, but may occur in the absence of wheezing. On auscultation, breath sounds may be normal with mild obstruction. With increasing airflow obstruction, breath sounds will be decreased initially at the lung bases, progressing to a widespread decrease and even becoming inaudible in very severe asthma. With increasing airflow obstruction, tachypnea, prolonged expiration, signs of accessory muscle use (eg, chest indrawing), hypoxemia and, in severe cases, altered level of consciousness (eg, agitation or apathy) can be observed. Cough is the most commonly observed sign and reported symptom, but it is not specific to asthma. Apart from viral respiratory infections, a chronic cough that occurs during sleep or is triggered by allergen exposures, exertion, laughing or crying increases the likelihood of asthma (15).

\section{Reversibility of airflow obstruction}

A hallmark of asthma is the reversibility of airflow obstruction (ie, a clear and timely response to asthma therapy). More specifically, reversibility is best defined as a documented response to short-acting $\beta_{2}$-agonists (SABA) (with or without oral corticosteroids) by health care professionals during an acute exacerbation (preferred diagnostic method). In children with no objective signs of airflow obstruction (ie, symptoms only), reversibility may be determined by convincing parental report of symptomatic response to a three-month therapeutic trial of a medium dose of inhaled corticosteroids with as-needed SABA (alternative diagnostic method), or convincingly reported and repeatedly observed response to as-needed SABA alone by parents (weaker, alternative diagnostic method) (Table 1). 
TABLE 1

\section{Operational diagnostic criteria for asthma in children one} to five years of age

1. Documentation of airflow obstruction

Preferred Documented wheezing and other signs of airflow obstruction by physician or trained health care practitioner

Alternative Convincing parental report of wheezing or other symptoms of airflow obstruction

2. Documentation of reversibility of airflow obstruction

Preferred Documented improvement in signs of airflow obstruction to $\mathrm{SABA} \pm$ oral corticosteroids* by physician or trained health care practitioner

Alternative $^{\dagger}$ Convincing parental report of symptomatic response to a 3-month trial of a medium dose of ICS (with as-needed SABA)*

Alternative $^{\ddagger}$ Convincing parental report of symptomatic response to SABA

\section{No clinical evidence of an alternative diagnosis}

*See Table 3 for further details regarding the recommended therapy or therapeutic trial; †'In children with frequent symptoms and/or one or more exacerbation requiring rescue oral corticosteroids or a hospital admission; ¥In children with mild intermittent symptoms and exacerbations, the diagnosis is only suggested because the accuracy of parental report of a short-term response to inhaled short-acting $\beta_{2}$-agonists (SABA) may be unreliable due to misperception and spontaneous improvement of another condition. Because this is a weaker alternative diagnostic method, confirmation by direct observation when symptomatic is preferred. ICS Inhaled corticosteroids

No alternative diagnosis

A thorough medical history and physical examination must be conducted, and medical conditions with similar presentations must be carefully considered to ensure that there is no alternative diagnosis. (Table 2). Additional investigations are not required for the diagnosis of asthma unless there is suspicion of an alternative diagnosis. A chest $\mathrm{x}$-ray may be indicated in specific instances to rule out other causes of wheezing or comorbidities.

Recurrent URTIs with postnasal drip is the most frequent cause of recurrent cough; it is not associated with wheeze or difficulty breathing. Croup presents with airflow obstruction in the upper airways with barking cough and inspiratory stridor; it is more common in children with asthma (and vice versa) (16). It may be difficult to distinguish asthma from bronchiolitis in young toddlers because they present with similar signs of airflow obstruction and viral respiratory illness. Although there is no definite age cut-off, bronchiolitis usually presents as the first episode of cough, wheezing and respiratory difficulty in an infant ( $<12$ months of age) (17) and is best treated with supportive care (18). Asthma usually starts in toddlers (one to three years of age). However, repeated $(\geq 2)$ wheezing episodes occurring before one year of age should raise the suspicion of asthma and prompt the consideration of a referral to a specialist for evaluation. In children $\geq 1$ year(s) of age, the best way to distinguish bronchiolitis from asthma is probably by the response to asthma medications.

\section{KEY MESSAGES}

3. Asthma can be diagnosed in children one to five years of age.

4. The diagnosis of asthma requires documentation of signs or symptoms of airflow obstruction, reversibility of obstruction (improvement in these signs or symptoms with asthma therapy) and no clinical suspicion of an alternative diagnosis.

5. Bronchiolitis usually presents as the first episode of wheezing in a child $<1$ year of age.

6. The diagnosis of asthma should be considered in children one to five years of age with recurrent asthma-like symptoms or exacerbations, even if triggered by viral infections.

TABLE 2

Signs/symptoms* (red flags) suggesting an alternative diagnosis to asthma

Signs and/or symptoms

Persistent nasal discharge

Stridor; noisy breathing worse when crying, eating, supine or with respiratory infection
Alternative diagnoses
Infectious/allergic rhinosinusitis ${ }^{\dagger}$
Upper airway narrowing:
(i) Infection: croup, tracheitis
(ii) Intrinsic: laryngomalacia, tracheal stenosis
(iii) Extrinsic: vascular ring, tumour

Acute onset of cough, wheeze or Foreign-body inhalation stridor during eating or playing; history of choking, recurrent pneumonia in same location

First episode wheeze in child $<1$ year

Sick contacts, focal signs on chest radiograph

Severe, paroxysms of cough, possibly initially associated with a 'whoop',

Premature birth, needed prolonged supplemental oxygen \pm mechanical ventilation

Symptoms since infancy, recurrent pneumonia, focal signs on chest radiograph

Chronic wet cough, clubbing, failure to thrive, recurrent pneumonia, onset in infancy, \pm steatorrhea

Neonatal respiratory distress, early onset year-round daily cough and nasal congestion \pm situs inversus Cough when supine, when feeding; vomiting after feeding, abdominal discomfort

Dysphagia, cough triggered by eating/drinking

Feeding intolerance, wet cough or noisy breathing after eating

Recurrent, persistent, severe or unusual infections

Cardiac murmur, cardiac failure, cyanosis when eating, failure to thrive, tachypnea, hepatomegaly

\section{Bronchiolitis $^{\dagger}$ \\ Pneumonia ${ }^{\dagger}$, atelectasis ${ }^{\dagger}$ tuberculosis, pertussis \\ Pertussis}

Bronchopulmonary dysplasia

Congenital pulmonary airway malformation

Bronchiectasis, cystic fibrosis

Primary ciliary dyskinesia

Gastroesophageal reflux disease ${ }^{\dagger}$

Eosinophilic esophagitis

Swallowing problem \pm aspiration

Immune dysfunction

Pulmonary edema due to:

(i) Acute myocarditis/pericarditis

(ii) Congenital heart disease

*Nonexhaustive list of signs and symptoms suggestive of possible alternative diagnoses, prompting additional investigations and/or a different management in the preschool child. Symptoms and signs listed may overlap among different diseases; 'Indicates the most frequent alternative diagnoses to, or comorbidities associated with, asthma

\section{DIAGNOSIS IN A CHILD PRESENTING WITH SIGNS OF AIRFLOW OBSTRUCTION (FIGURE 1)}

When a child exhibits wheezing or other signs of airflow obstruction on presentation (as expected in the acute care setting), the documentation by a physician (or other trained health care practitioner) of signs of airflow obstruction and improvement in these signs with asthma therapy, in the absence of clinical suspicion of an alternative diagnosis, is the preferred diagnostic approach. The diagnosis of asthma is based on recurrent $(\geq 2)$ asthma-like exacerbations (episodes with documented signs) or symptoms (reported). In case of a first asthma-like exacerbation, the diagnosis of asthma is suspected, and can be confirmed with recurrence of asthma-like signs or symptoms and response to asthma therapy. 


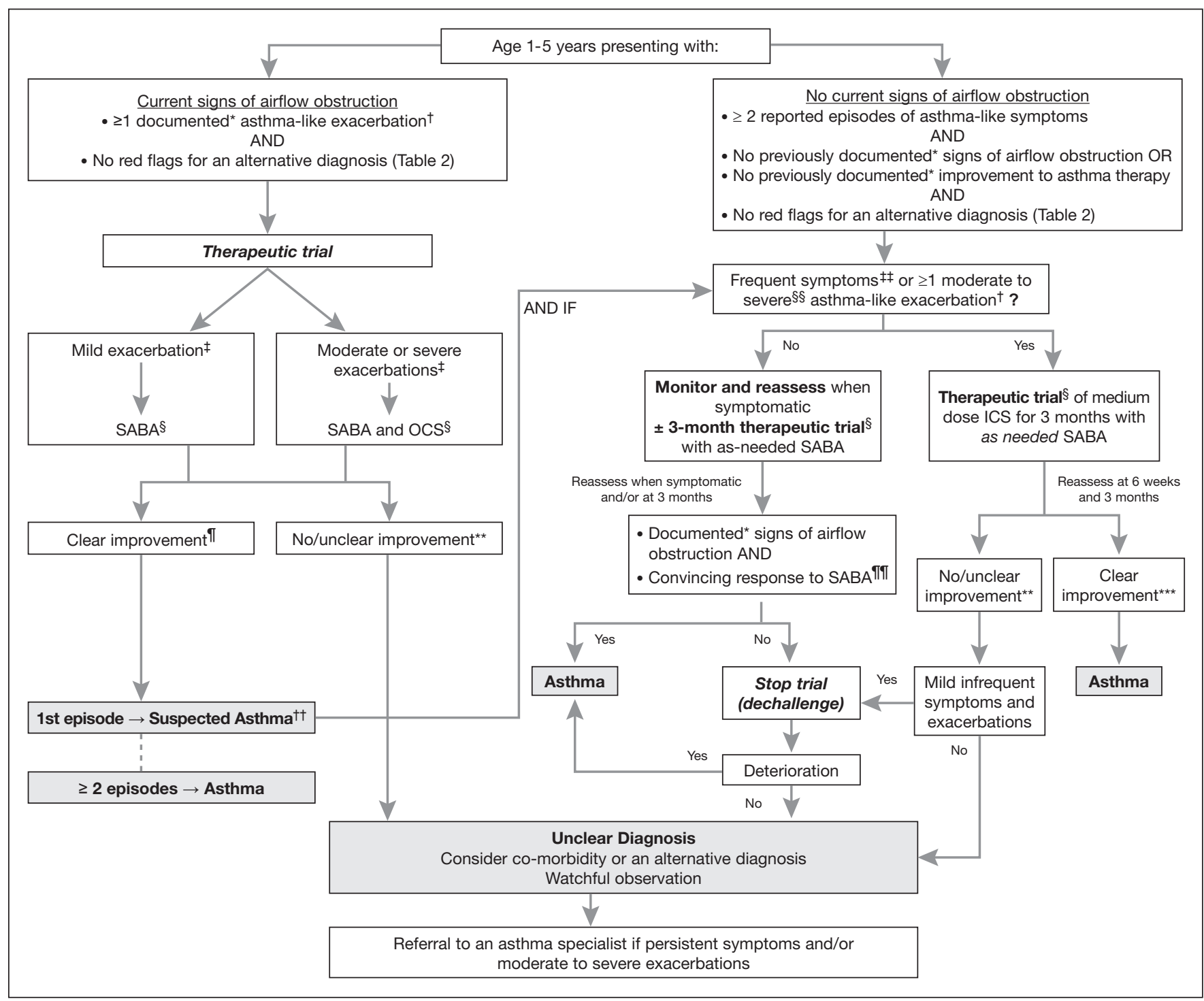

Figure 1) Diagnosis algorithm for children one to five years of age. *Documentation by a physician or trained health care practitioner; ${ }^{\dagger}$ Episodes of wheezing with/without difficulty breathing; ${ }^{*}$ Severity of an exacerbation documented by clinical assessment of signs of airflow obstruction, preferably with the addition of objective measures such oxygen saturation and respiratory rate, and/or validated score such as the Pediatric Respiratory Assessment Measure (PRAM) score;

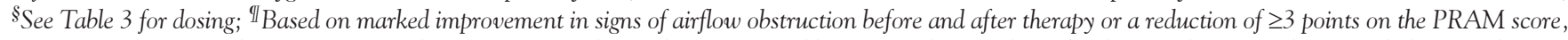
recognizing the expected time response to therapy; **A conclusive therapeutic trial hinges on adequate dose of asthma medication, adequate inhalation technique, diligent documentation of the signs and/or symptoms, and timely medical reassessment; if these conditions are not met, consider repeating the treatment or therapeutic trial; ††The diagnosis of asthma is based on recurrent $(\geq 2)$ episodes of asthma-like exacerbations (documented signs) and/or symptoms. In case of a first occurrence of exacerbation with no previous asthma-like symptoms, the diagnostic of asthma is suspected and can be confirmed with re-occurrence of asthma-like symptoms or exacerbations with response to asthma therapy; $\geq 8$ days/month with asthma-like symptoms; $\$$ Episodes requiring rescue oral corticosteroids (OCS) or a hospital admission; III In this age group, the diagnostic accuracy of parental report of a short-term response to as-needed short-acting $\beta_{2}$-agonist (SABA) may be unreliable due to misperception and/or spontaneous improvement of another condition. Documentation of airflow obstruction and reversibility when symptomatic, by a physician or trained health care practitioner, is preferred; ***Based on $50 \%$ fewer moderate/severe exacerbations, shorter and milder exacerbations, and fewer, milder symptoms between episodes. ICS Inhaled corticosteroid

Clinical improvement in the signs of airflow obstruction after inhaled SABA and/or oral corticosteroids observed by a health care practitioner provides direct evidence of reversibility (19) (Table 3). With a peak SABA effect at $20 \mathrm{~min}$, one would observe a rapid response to a single appropriate dose of SABA in children with mild clinical findings and to repeated (two to three) doses of SABA administered over a $60 \mathrm{~min}$ period in those with moderate and severe airflow obstruction (20). A suboptimal response to SABA is anticipated if most of the airflow obstruction is not due to bronchospasm (but rather inflammation), particularly in a child with long-standing, poorly controlled asthma. Response to oral corticosteroids is expected to begin within $4 \mathrm{~h}$ of administration (21), although the maximal effect may be documented after several days of therapy $(22,23)$, which may be difficult to distinguish from spontaneous improvement over time.

Documenting objective response to therapy

Improvement with asthma therapy can be assessed by noting changes in signs of airflow obstruction before and after therapy, recognizing the expected time response to therapy (Table 3) $(20,21,23,24)$. Use of objective measures (ie, oxygen saturation in room air, respiratory rate) 


\begin{tabular}{|c|c|c|c|c|}
\hline Child presentation & Agent & Dose & Doses/day & $\begin{array}{c}\text { Time to } \\
\text { reassessment }\end{array}$ \\
\hline \multicolumn{5}{|c|}{ Signs of airflow obstruction (preferred) } \\
\hline Mild clinical findings* & Inhaled salbutamol & $\geq 4$ puffs $^{\dagger}$ & 1st dose & $30 \mathrm{~min}$ \\
\hline Moderate or severe exacerbation* & Inhaled salbutamol & $\geq 4$ puffs $^{\dagger}$ & $\begin{array}{l}2-3 \text { doses } \\
\text { within } 60 \mathrm{~m}\end{array}$ & $60 \min$ \\
\hline
\end{tabular}

\begin{tabular}{|c|c|c|c|c|}
\hline & \multicolumn{4}{|l|}{ Oral corticosteroids ${ }^{\ddagger}$} \\
\hline & Prednisone/prednisolone (oral) & $1-2 \mathrm{mg} / \mathrm{kg}(\text { maximum } 50 \mathrm{mg})^{\ddagger}$ & 1st dose & $3 \mathrm{~h}$ to $4 \mathrm{~h}$ \\
\hline & Dexamethasone & $0.15-0.60 \mathrm{mg} / \mathrm{kg}(\text { maximum } 10 \mathrm{mg})^{\ddagger}$ & 1st dose & $3 \mathrm{~h}$ to $4 \mathrm{~h}$ \\
\hline \multicolumn{5}{|l|}{ No signs of airflow obstruction (alternative) } \\
\hline Mild intermittent symptoms or exacerbations ${ }^{\S}$ & Inhaled salbutamol & 2 puffs every $4 \mathrm{~h}$ to $6 \mathrm{~h}$ & As needed & $30 \mathrm{~min}$ \\
\hline \multirow[t]{5}{*}{ Frequent symptoms or moderate or severe exacerbations } & Inhaled salbutamol & 2 puffs every $4 \mathrm{~h}$ to $6 \mathrm{~h}$ & As needed & $30 \min ^{* *}$ \\
\hline & Daily inhaled corticosteroids & & & \\
\hline & Beclomethasone dipropionate & $100 \mu \mathrm{g}$ & Twice daily & 3 months ${ }^{\dagger \dagger}$ \\
\hline & Ciclesonide & $200 \mu g$ & Daily & 3 months ${ }^{\dagger \dagger}$ \\
\hline & Fluticasone propionate & $100-125 \mu \mathrm{g}$ & Twice daily & 3 months ${ }^{\dagger \dagger}$ \\
\hline
\end{tabular}

Unless indicated otherwise, all medications are administered by metered-dose inhaler (MDI) with an age-appropriate valved spacer under health care professional supervision (top panel) or by parents (bottom panel); doses are reported ex-valve. Medications listed in shaded area are not approved for use in this age group by Healh Canada with the exception of beclomethasone dipropionate approved for use in children $\geq 5$ years of age. Because delivery by MDI is preferred, budesonide is not included in this table because it is only available for use by nebulization in this age group in Canada. *Severity of signs may be based on national guidelines for severity assessment (19) or on the Pediatric Respiratory Assessment Measure (PRAM, mild: PRAM 0-3; moderate: PRAM 4-7; severe: PRAM 8-12) (25,26); ${ }^{\dagger}$ Dosage according to age- or weightspecific emergency treatment protocol (19); ¥Oral prednisone (or prednisolone) may be given at a dose of $1 \mathrm{mg} / \mathrm{kg}$ or $2 \mathrm{mg} / \mathrm{kg}$ of three- to five-day course. Oral dexamethasone may be given either at a dose of $0.15 \mathrm{mg} / \mathrm{kg}$ to $0.3 \mathrm{mg} / \mathrm{kg}$ as the first dose of a subsequent two- to four-day course of prednisone or at a dose of $0.6 \mathrm{mg} / \mathrm{kg}$ as part of a one- or two-day course (21-24); §Refers to asthma-like symptoms of mild severity occurring $<8$ days/month and mild exacerbations requiring no rescue oral corticosteroids or admission and lasting hours to a few days; "IFrequent asthma-like symptoms occurring $\geq 8$ days/month; moderate or severe exacerbations refer to episodes with asthma-like signs requiring rescue oral corticosteroids or hospital admission; **As monitored by parents for subsequent reporting at the medical reassessment; t+With medical reassessment (or another health care practitioner contact) at 6 weeks to ensure adherence to asthma medication and diary completion

and/or a standardized clinical score such as the Pediatric Respiratory Assessment Measure (PRAM), in which a change of 3 points is considered to be clinically important $(25,26)$, reduces the subjectivity of the assessment (Table 4). Recurrence of signs of obstruction after the effects of SABA have lapsed is confirmatory.

\section{DIAGNOSIS IN A CHILD PRESENTING WITHOUT \\ SIGNS OF AIRFLOW OBSTRUCTION (FIGURE 1)}

Many children presenting in ambulatory care are not acutely ill and their physical examination is typically normal. On occasion, convincing signs of airflow obstruction can be provoked after a deep inspiration or exercise. However, the physical examination remains relatively insensitive to identifying airflow obstruction, particularly if the obstruction is long standing. In this case, previous documentation of wheezing or other signs of airflow obstruction by a trained health care practitioner, and improvement with SABA and/or oral corticosteroid when acutely ill, acceptably replaces one's own evaluation.

In children presenting with no signs of airflow obstruction, a diagnosis of asthma is suspected if they experienced recurrent $(\geq 2)$ episodes with asthma-like symptoms and no previously documented signs of airflow obstruction or reversibility, and no suspicion of an alternative diagnosis. Asthma is also suspected if there has been a single episode of airflow obstruction with reversibility documented by a trained health care practitioner with no previous or subsequent episodes with asthma-like signs or symptoms. Confirmation of diagnosis may be obtained by a therapeutic trial.

Children who experience mild and infrequent symptoms ( $<8$ days) month) and only mild exacerbations (lasting hours to a few days, without rescue oral corticosteroids or hospital admission), convincing parental report of a rapid and repeatedly observed symptomatic response to as-needed SABA alone is suggestive of asthma, but is a weaker alternative diagnostic method (Table 3 ). For increased diagnostic certainty, these children should be monitored and reassessed by a trained health care practitioner for signs of airflow obstruction and reversibility when symptomatic.
In children with frequent symptoms ( $\geq 2$ days/week [3] or $\geq 8$ days/ month) or $\geq 1$ moderate or severe asthma-like exacerbation (ie, treated with oral corticosteroids or a hospital admission), a therapeutic trial with a medium $(200 \mu \mathrm{g}$ to $250 \mu \mathrm{g})$ daily dose of ICS and as-needed SABA, administered by metered-dose inhaler, is suggested (Table 3 ).

A trial of a medium-dose ICS (Table 5) for determination of reversibility of airflow obstruction is suggested because daily ICS are the preferred asthma controller medications for the management of both recurrent episodic exacerbations and persistent asthma symptoms, with an efficacy that has been well demonstrated in systematic reviews of randomized controlled trials $(13,27)$. Because ICS have an onset of action within one to four weeks (28), and most trials demonstrated ICS efficacy within three to six months $(13,27)$, a minimum therapeutic trial of three months is recommended. In this age group, budesonide and fluticasone have been studied the most extensively and have been found to be clinically effective $(19,27)$, with fluticasone showing less effect on growth than beclomethasone dipropionate and budesonide at equivalent doses (29). Because delivery by metered-dose inhaler is preferred, budesonide is not recommended because it is only available for use by nebulization in Canada in children $<6$ years of age. There is only one published trial of ciclesonide (30) and none with mometasone in preschoolers. Because of weaker evidence compared with ICS (27), montelukast is not recommended for a therapeutic trial.

Documenting symptomatic response to therapy

A conclusive therapeutic trial hinges on adherence to asthma medication, adequate inhalation technique, diligent documentation of signs and/or symptoms, and timely medical reassessment. Because it is easier to interpret, the therapeutic trial should preferably be conducted during the season when the child is most symptomatic. To document a change in the frequency and severity of symptoms between and during asthma-like exacerbations, we encourage prospective parental monitoring of key elements of asthma control, including daytime and nighttime symptoms, rescue SABA use, effort limitation, absenteeism from usual activities, and exacerbations requiring unscheduled medical 
TABLE 4

Pediatric Respiratory Assessment Measure (PRAM) scoring table

\begin{tabular}{|c|c|c|}
\hline \multirow[t]{3}{*}{ Oxygen saturation } & $\geq 95 \%$ & 0 \\
\hline & $92 \%-94 \%$ & 1 \\
\hline & $<92 \%$ & 2 \\
\hline \multirow[t]{2}{*}{ Suprasternal retraction } & Absent & 0 \\
\hline & Present & 2 \\
\hline \multirow[t]{2}{*}{ Scalene muscle contraction } & Absent & 0 \\
\hline & Present & 2 \\
\hline \multirow[t]{4}{*}{ Air entry* } & Normal & 0 \\
\hline & $\downarrow$ At the base & 1 \\
\hline & $\begin{array}{l}\downarrow \text { At the apex and the } \\
\text { base }\end{array}$ & 2 \\
\hline & Minimal or absent & 3 \\
\hline \multirow[t]{4}{*}{ Wheezing $^{\dagger}$} & Absent & 0 \\
\hline & Expiratory only & 1 \\
\hline & $\begin{array}{l}\text { Inspiratory } \\
\text { ( } \pm \text { expiratory) }\end{array}$ & 2 \\
\hline & $\begin{array}{l}\text { Audible without } \\
\text { stethoscope or silent } \\
\text { chest (minimal or } \\
\text { no air entry) }\end{array}$ & 3 \\
\hline
\end{tabular}

PRAM score (maximum 12)

\begin{tabular}{lccc}
\hline Score & $0-3$ & $4-7$ & $8-12$ \\
\hline Severity & Mild & Moderate & Severe \\
\hline
\end{tabular}

Adapted from Ducharme FM, Chalut D, Plotnick L, et al. The Pediatric Respiratory Assessment Measure: A valid clinical score for assessing acute asthma severity from toddlers to teenagers. J Pediatr 2008;152(4):476-80, 480.e1. This tool is available at <www.chu-sainte-justine.org/childasthmatools>. *In case of asymmetry, the most severely affected (apex-base) lung field (right or left, anterior or posterior) will determine the rating of the criterion; +In case of asymmetry, the two most severely affected auscultation zones, irrespectively of their location (right upper lobe, right middle lobe, right lower lobe, left upper lobe, left lower lobe), will determine the rating of the criterion. $\downarrow$ Decreased

visits, oral corticosteroids and/or hospital admission. Recording in a diary is suggested to avoid inaccurate recall (31), although it may be subject to missing or falsified data $(32,33)$. The reliability of parental report of treatment response to ICS has not been formally examined nor has the ability of this approach been formally tested to accurately distinguish children with asthma from those without asthma in the community setting; however, parental report is widely used in clinical trials of ICS showing efficacy in preschoolers. Recognizing that parental adherence to daily controller and diary completion drops significantly over time, an initial follow-up is recommended approximately half way (six weeks) through the trial.

A clear and consistent improvement in the frequency and severity of symptoms and/or exacerbations during a therapeutic trial of asthma controller medication is required to confirm reversibility of airflow obstruction (ie, response to therapy). The magnitude of change required to meet the definition of a satisfactory clinical response has not been formally examined. However, based on trials of medium doses of daily ICS, a reduction of approximately $50 \%$ in the number of exacerbations requiring oral corticosteroids (RR 0.57 [95\% CI 0.40 to 0.80 ]) is expected, with a shorter duration and severity of exacerbations (27) and fewer symptoms between exacerbations. We acknowledge that reversibility could also be suggested by the convincingly reported and repeatedly observed by parents of a rapid shortterm response to SABA when symptomatic (Table 3); this has been included as a weaker alternative diagnostic criterion for reversibility (Table 1). Clinicians should be aware that the perception of children
TABLE 5

Inhaled corticosteroid (ICS) dosing categories* in children one to five years of age

\begin{tabular}{lcc}
\hline & \multicolumn{2}{c}{ Daily ICS dose, micrograms $(\mathbf{m c g})^{\dagger}$} \\
\cline { 2 - 3 } Corticosteroid (trade name) & Low & Medium \\
\hline${\text { Beclomethasone }\left(\mathrm{QVAR}^{\circledR}\right)}^{\text {Ciclesonide }^{\ddagger}\left(\text { Alvesco }^{\circledR}\right)}$ & 100 & 200 \\
Fluticasone $\left(\right.$ Flovent $\left.^{\circledR}\right)$ & 100 & 200 \\
\hline
\end{tabular}

*Proposed dosing categories are based on a combination of approximate dose equivalency as well as safety and efficacy data rather than the available product formulations. Shaded area indicates that these medications are not approved for use in this age group by Health Canada with the exception of Beclomethasone (QVAR), which is approved for use in children $\geq 5$ years of age. Because delivery by metered-dose inhaler is preferred, budesonide is not included in this table because it is only available for use by nebulization in Canada in children $<6$ years of age. High doses of ICS are not recommended in this age group and referral to an asthma specialist is suggested if asthma is not controlled on a medium dose of ICS; t The ICS doses are reported ex-valve as the total daily dose; they should be divided in half for twice-daily administration, except where indicated otherwise. ICS are to be administered by metered-dose inhaler with an age-appropriate valved spacer; ${ }^{\ddagger}$ Licensed for once daily dosing in Canada; §Fluticasone is not licensed for once-daily dosing in Canada but $125 \mu \mathrm{g}$ once daily is sometimes used to improve adherence over twice-daily use of $50 \mu \mathrm{g}$

(34) and adults (35) with respect to bronchodilator response may be unreliable, and short-term improvement may be spontaneous or due to the natural course of an alternative condition. If a satisfactorily conducted trial remains inconclusive, the presence of a comorbidity and/ or an alternative diagnosis should be reconsidered.

\section{Dechallenge}

In children with mild infrequent symptoms and mild episodes with asthma-like signs in whom improvement with a therapeutic trial is unclear, a period of observation after stopping therapy for three to six months or until recurrence of symptoms, whichever occurs first, is suggested. Parental report of aggravation of symptoms on withdrawal of therapy is suggestive of the diagnosis of asthma.

\section{KEY MESSAGES}

7. In children one to five years of age with recurrent $(\geq 2)$ episodes of asthma-like symptoms and wheezing on presentation, direct observation of improvement with inhaled bronchodilator (with or without oral corticosteroids) by a physician or trained health care practitioner confirms the diagnosis (preferred diagnostic method).

8. Children one to five years of age with recurrent $(\geq 2)$ episodes of asthma-like symptoms, no wheezing on presentation, frequent symptoms or any moderate or severe exacerbation warrant a three-month therapeutic trial with a medium daily dose of ICS (with as-needed SABA). Clear consistent improvement in the frequency and severity of symptoms and/or exacerbations confirms the diagnosis (alternative diagnostic method).

9. Children one to five years of age with recurrent $(\geq 2)$ episodes of asthma-like symptoms, no wheezing on presentation, infrequent symptoms, and mild exacerbations can be monitored and re-assessed by a health care practitioner when symptomatic. Alternatively, a therapeutic trial with as-needed SABA is suggested. Convincing parental report of a rapid and repeatedly observed response to SABA suggests the diagnosis (weaker alternative diagnostic method)

10. To adequately interpret a therapeutic trial, clinicians should ascertain adherence to asthma therapy, inhalation technique and parental report of monitored symptoms, at an appropriately timed medical reassessment. 


\section{WHEN TO REFER TO A SPECIALIST}

Recommendations for specialty referral are summarized in Table 6 $(3,36-40)$. Preschool lung function testing, available in some pediatric academic centres, can be helpful to confirm the diagnosis (41-44). Allergy testing is suggested in a child with persistent symptoms to assess the possible role of environmental allergens and provide advice about implementation of avoidance strategies $(39,45)$.

\section{KEY MESSAGE}

11. Referral to an asthma specialist is recommended in children one to five years of age with diagnostic uncertainty, suspicion of comorbidity, poor symptom and exacerbation control despite ICS at daily doses of $200 \mu \mathrm{g}$ to $250 \mu \mathrm{g}$, a life-threatening event (requiring intensive care admission and/or intubation) and/or for allergy testing to assess the possible role of environmental allergens.

\section{Nonpharmacological}

\section{APPROACH TO MANAGEMENT}

Once a diagnosis of asthma has been confirmed, families and caregivers should receive asthma education that includes a written selfmanagement plan emphasizing adherence to asthma medication, and appropriate inhaler with spacer technique instructions (2). For children one to three years of age, a spacer with a correctly sized facemask is preferred. For children four to five years of age, consideration to use a spacer with a mouthpiece is encouraged if the child can form a good seal around the mouthpiece and breathe in through the mouth as observed by a trained health care professional. Avoidance of irritants, such as cigarette smoke, is important as well as environmental aeroallergens if the child is sensitized.

\section{Pharmacological}

Once the diagnosis is confirmed, ICS taken every day at the lowest effective dose (Table 5) is the preferred first-line management for children presenting with persistent symptoms ( $>8$ days/month) and/or moderate or severe exacerbations (ie, requiring rescue oral corticosteroids or hospital admission) $(13,27)$. If the patient has received a therapeutic trial with a medium dose of ICS, this entails downward titrating to the lowest effective dose after control has been achieved (Figure 2). Until more evidence supporting their effectiveness is available, the following three commonly used strategies are not advocated and/or should be avoided: daily leukotriene receptor antagonists, which are less effective than ICS and should remain a second-line option (46); stepping-up the daily dose of ICS during URTI, which remains untested in preschoolers; and the intermittent use of asthma controller medications at the onset of symptoms (eg, montelukast or low or medium doses of ICS) that has not been convincingly shown to reduce the number or severity of asthma exacerbations $(27,47,48)$. In contrast, use of pre-emptive high-dose ICS at the onset of symptoms is effective in reducing the severity and duration of exacerbations in preschoolers with moderate or severe viral-induced asthma; however, due to the risk for overuse and potential side effects, this treatment should be reserved for asthma specialists and only if daily ICS fails (49). Children with mild infrequent symptoms ( $\leq 8$ days/month) and no or mild exacerbation (ie, no rescue oral corticosteroids or admission and lasting hours to a few days), as-needed SABA may be sufficient to maintain control.

\section{Monitoring}

Asthma control should be assessed every three to four months using the same criteria as for school-age children and adults (2). An exacerbation requiring rescue systemic corticosteroids or hospitalization is an indication of suboptimal management and should prompt reassessment. Once adequate control has been sustained over the three months before reassessment, despite exposure to the child's typical unavoidable asthma triggers (eg, URTI, cold air), consideration should

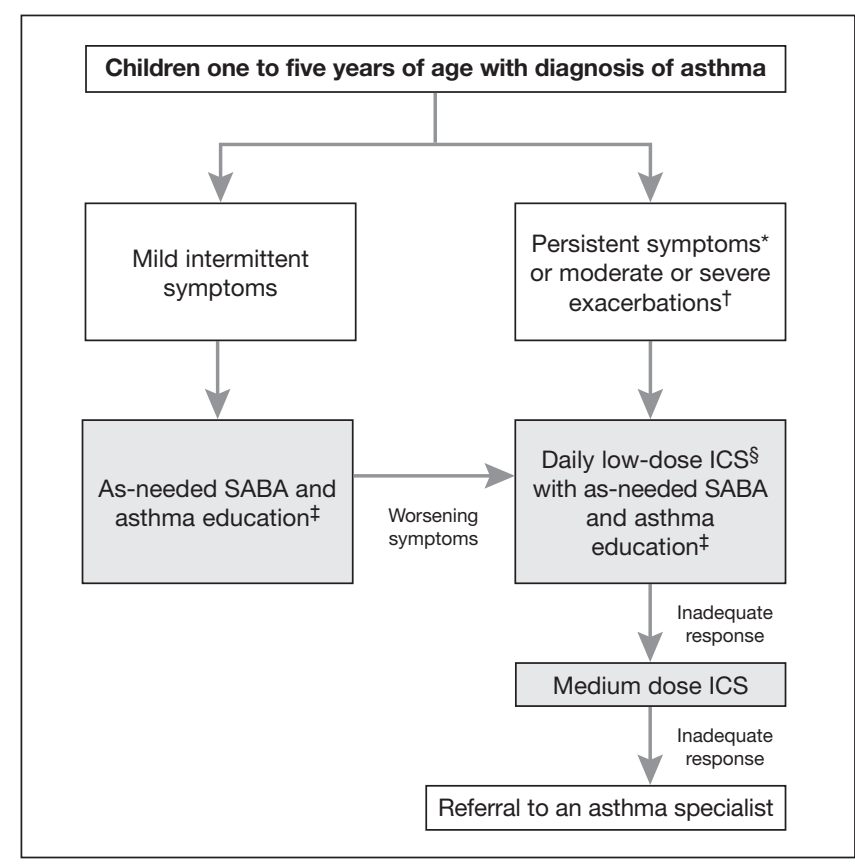

Figure 2) Treatment algorithm for preschoolers with asthma. *Symptoms occurring $\geq 8$ days/month, $\geq 8$ days/month with use of inhaled short-acting $\beta_{2}$-agonists (SABA), $\geq 1$ night awakening due to symptoms/month, any exercise limitation/month or any absence from usual activities to asthma symptoms; 'Episodes requiring rescue oral corticosteroids or hospital admission; Asthma education including environmental control and a written self-management plan; SInhaled corticosteroids (ICS) are more effective than leukotriene receptor antagonists (LTRA)

be given to incrementally stepping down their medication to the lowest effective dose. Given the high rate of symptom resolution in this age group, a trial off medication can be attempted when symptoms are minimal on a low dose of ICS during the season when the child is usually most symptomatic.

\section{KEY MESSAGE}

12. Daily ICS at the lowest effective dose is the preferred first-line management for asthma once the diagnosis is confirmed and control has been achieved.

\section{KNOWLEDGE TRANSFER AND TOOLS FOR PRACTICE}

- The present document is available for download at www.respiratoryguidelines.ca and www.pulsus.com.

- A slide deck for teaching and self-learning as well as a brochure for health care professionals and students is available at <www.respiratoryguidelines.ca> under the 'Tools and Resources' tab.

- The CTS plans to develop, in collaboration with McGill University (Montreal, Quebec), a mobile application to raise awareness of our 12 key messages and other guidelines' recommendations, for clinical practice.

- Several forms of patient diaries, for use in the context of a therapeutic trial, are available to document response.

- For the acute care setting, an online teaching module on PRAM is available at www.chu-sainte-justine.org/pram.

The CTS Asthma Clinical Assembly welcomes the opportunity to partner with other organizations and stakeholders in the development of educational tools and resources that support implementation and uptake of these key messages with various targeted groups. 


\section{TABLE 6 \\ Reasons for referral to an asthma specialist for consultation or comanagement}

Diagnostic uncertainty or suspicion of comorbidity

Repeated $(\geq 2)$ exacerbations requiring rescue oral corticosteroids or hospitalization or frequent symptoms ( $\geq 8$ days/month) despite moderate $(200 \mu \mathrm{g}$ to $250 \mu \mathrm{g})$ daily doses of inhaled corticosteroids

Life-threatening event such as an admission to the intensive care unit Need for allergy testing to assess the possible role of environmental allergens Other considerations (parental anxiety, need for reassurance, additional education)

\section{CONCLUSION}

Asthma is diagnosed in children one to five years of age with recurrent asthma-like episodes, using signs (or convincingly-reported symptoms) of airflow obstruction and reversibility of obstruction with asthma therapy, in the absence of clinical evidence of an alternative diagnosis. Objective documentation of airflow obstruction and reversibility by a physician or other trained health care practitioner is preferred. We offer a pragmatic diagnostic algorithm, depending on the presence or absence of signs of airflow obstruction on presentation to children into asthma, suspected asthma or unclear diagnosis (Figure 1). Once the diagnosis is confirmed, daily low-dose ICS $(100 \mu \mathrm{g} /$ day to $125 \mu \mathrm{g} /$ day $)$ with as-needed SABA, is the preferred management strategy in preschoolers with persistent symptoms and/or moderate or severe exacerbations and as-needed SABA alone for those with mild intermittent symptoms and exacerbations (Figure 2).

\section{MONITORING ADHERENCE TO KEY MESSAGES}

The following parameters may be used to monitor or audit adherence with some of the key recommendations contained in the present position statement:

- Decreased use of terms such as 'bronchospasm', 'reactive airway disease', 'wheezy bronchitis' and 'happy wheezer' in medical records.

- Clear documentation in the medical charts of preschoolers with asthma-like exacerbations of the presence or absence of: signs and symptoms of airflow obstruction; improvement with therapy; and clinical suspicion of another condition.

- In children one to five years of age with frequent symptoms and/or moderate or severe exacerbations, records of direct observation of response of signs of airflow obstruction to SABA to confirm the diagnosis of asthma.

- In children one to five years of age with frequent symptoms and/or moderate or severe exacerbations presenting with no signs of airflow obstruction, records of the use of a three-month therapeutic trial with daily ICS to confirm the diagnosis of asthma.

- Increased proportion of children one to five years of age with recurrent $(\geq 2)$ asthma-like exacerbations, in whom the diagnosis of asthma is made, even if episodes are triggered by viral respiratory infections.

\section{FUTURE DIRECTIONS}

- Documentation of the impact of these new diagnostic criteria on the accuracy and frequency of the diagnosis of asthma, medication use and health outcomes in preschoolers.

- Exploring parental perception of the proposed diagnostic approach.

- Documenting the frequency of the adequate medical documentation of the three asthma criteria by health care professionals in various settings.

- Improving the ability and documenting the reliability of parental documentation of symptoms in written and/or electronic diaries or alternative formats.

- Improvement in the reliability and feasibility of preschool lung function testing to objectively diagnose asthma in preschoolers, including better reference equations to identify those with airflow obstruction, evidence-based grading of the severity of airflow obstruction, and identification of the magnitude of between-visit improvement indicating a significant treatment response.

- Exploring the impact of portable preschool lung function testing in ambulatory care on asthma control, risk of future exacerbations and lung function trajectories of preschool-age children who experience asthma-like exacerbations.

ACKOWLEDGEMENTS: The authors acknowledge the support provided by the Canadian Thoracic Society and the Canadian Paediatric Society for this initiative. The authors sincerely thank Drs Paul Brand, Tom Kovesi, Rod Lim, Tim O'Callahan, Catherine Lemière, Diane Lougheed, Richard Leigh, Chris Licskai and Samir Gupta for their constructive comments in reviewing this manuscript. They are indebted to Meriem Bougrassa for coordinating this initiative, Annie Théoret for assistance in the manuscript preparation and Risa Shorr for the literature search.

EDITORIAL INDEPENDENCE: The CTS Asthma Clinical Assembly is accountable to the CTS Respiratory Guidelines Committee and the CTS Board of Directors, and is functionally and editorially independent from any funding sources of the CTS. No funders played a role in the collection, review analysis or interpretation of the literature, or in any decisions regarding the key messages presented in this document.

DISCLOSURES: Members of the working group declared potential conflicts of interest at the time of appointment, which were updated throughout the development process in accordance with CTS Conflict of Interest Disclosure Policy. Individual member conflict of interest statements are posted at www.respiratoryguidelines.ca/guideline/asthma

KNOWLEDGE TRANSFER AND TOOLS FOR PRACTICE

1. http://asthmacentre.pe.ca/admin/documents/images/temp/Sdfinal.pdf

2. http://www.chu-sainte-justine.org/Applications/asthmatools/EN/ index.html?childfamily

\section{REFERENCES}

1. Hughes D. Recurrent pneumonia... Not! Paediatr Child Health 2013;18:459-60.

2. Lougheed MD, Lemiere C, Ducharme FM, et al. Canadian Thoracic Society 2012 guideline update: Diagnosis and management of asthma in preschoolers, children and adults. Can Respir J 2012;19:127-64

3. GINA Global Initiative for Asthma P. Global strategy for asthma management and prevention. Global Initiative for Asthma 2014 $<$ www.ginasthma.org/> (Accesssed May 2014).

4. Inoue Y, Shimojo N. Epidemiology of virus-induced wheezing/ asthma in children. Front Microbiol 2013;4:391.

5. Castro-Rodriguez JA, Holberg CJ, Wright AL, Martinez FD. A clinical index to define risk of asthma in young children with recurrent wheezing. Am J Respir Crit Care Med 2000;162:1403-6.

6. Martinez FD, Wright AL, Taussig LM, Holberg CJ, Halonen M, Morgan WJ. Asthma and wheezing in the first six years of life. The Group Health Medical Associates. N Engl J Med 1995;332:133-8.

7. Leonardi NA, Spycher BD, Strippoli M-PF, Frey U, Silverman M, Kuehni CE. Validation of the Asthma Predictive Index and comparison with simpler clinical prediction rules. J Allergy Clin Immunol 2011;127:1466-72.e6.

8. Fouzas S, Brand PL. Predicting persistence of asthma in preschool wheezers: Crystal balls or muddy waters? Paediatr Respir Rev 2013;14:46-52.

9. Lougheed MD, Garvey N, Chapman KR, et al. Variations and gaps in management of acute asthma in Ontario emergency departments. Chest 2009;135:724-36.

10. Lougheed MD, Garvey N, Chapman KR, et al. The Ontario Asthma Regional Variation Study: Emergency department visit rates and the relation to hospitalization rates. Chest 2006;129:909-17.

11. Grad R, Morgan WJ. Long-term outcomes of early-onset wheeze and asthma. J Allergy Clin Immunol 2012;130:299-307.

12. Saglani S, Payne DN, Zhu J, et al. Early detection of airway wall remodeling and eosinophilic inflammation in preschool wheezers. Am J Respir Crit Care Med 2007;176:858-64. 
13. Castro-Rodriguez JA, Rodrigo GJ. Efficacy of inhaled corticosteroids in infants and preschoolers with recurrent wheezing and asthma: A systematic review with meta-analysis. Pediatrics 2009;123:e519-e25.

14. Cane RS, Ranganathan SC, McKenzie SA. What do parents of wheezy children understand by "wheeze"? Arch Dis Child 2000;82:327-32.

15. van Asperen PP. Cough and asthma. Paediatr Respir Rev 2006;7:26-30.

16. Gurwitz D, Corey M, Levison H. Pulmonary function and bronchial reactivity in children after croup. Am Rev Respir Dis 1980;122:95-9.

17. Koehoorn M, Karr CJ, Demers PA, Lencar C, Tamburic L, Brauer M. Descriptive epidemiological features of bronchiolitis in a population-based cohort. Pediatrics 2008;122:1196-203.

18. Oymar K, Skjerven HO, Mikalsen IB. Acute bronchiolitis in infants, a review. Scand J Trauma Resusc Emerg Med 2014;22:23.

19. Ortiz-Alvarez O, Mikrogianakis A; Canadian Paediatric Society ACC. Managing the paediatric patient with an acute asthma exacerbation. Paediatr Child Health 2012;17:251-6.

20. Cates CJ, Welsh EJ, Rowe BH. Holding chambers (spacers) versus nebulisers for beta-agonist treatment of acute asthma. Cochrane Database Syst Rev 2013;(9):CD000052.

21. Rowe BH, Spooner C, Ducharme FM, Bretzlaff JA, Bota GW. Early emergency department treatment of acute asthma with systemic corticosteroids. Cochrane Database Syst Rev 2008:CD002178.

22. Rowe BH, Spooner CH, Ducharme FM, Bretzlaff JA, Bota GW. Corticosteroids for preventing relapse following acute exacerbations of asthma. Cochrane Database Syst Rev 2001:CD000195.

23. Shefrin AE, Goldman RD. Use of dexamethasone and prednisone in acute asthma exacerbations in pediatric patients. Can Fam Physician 2009;55:704-6.

24. Keeney GE, Gray MP, Morrison AK, et al. Dexamethasone for acute asthma exacerbations in children: A meta-analysis. Pediatrics 2014;133:493-9.

25. Ducharme FM, Chalut D, Plotnick L, et al. The pediatric respiratory assessment measure: A valid clinical score for assessing acute asthma severity from toddlers to teenagers. J Pediatr 2008;152:476-80.

26. Chalut DS, Ducharme FM, Davis GM. The preschool respiratory assessment measure (PRAM): A responsive index of acute asthma severity. J Pediatr 2000;137:762-8.

27. Ducharme FM, Tse SM, Chauhan B. Diagnosis, management, and prognosis of preschool wheeze. Lancet 2014;383:1593-604.

28. Bisgaard H, Gillies J, Groenewald M, Maden C. The effect of inhaled fluticasone propionate in the treatment of young asthmatic children: A dose comparison study. Am J Respir Crit Care Med 1999;160:126-31.

29. Zhang L, Prietsch SO, Ducharme FM. Inhaled corticosteroids in children with persistent asthma: Effects on growth. Cochrane Database Syst Rev 2014;7:CD009471.

30. Brand PL, Luz Garcia-Garcia M, Morison A, Vermeulen JH, Weber HC. Ciclesonide in wheezy preschool children with a positive asthma predictive index or atopy. Respir Med 2011;105:1588-95.

31. Okupa AY, Sorkness CA, Mauger DT, Jackson DJ, Lemanske RF Jr. Daily diaries vs retrospective questionnaires to assess asthma control and therapeutic responses in asthma clinical trials: Is participant burden worth the effort? Chest 2013;143:993-9.
32. Butz A. Use of health diaries in pediatric research. J Pediatr Health Care 2004;18:262-3.

33. Stone AA, Shiffman S, Schwartz JE, Broderick JE, Hufford MR. Patient compliance with paper and electronic diaries. Control Clin Trials 2003;24:182-99.

34. Couriel JM, Demis T, Olinsky A. The perception of asthma. Aust Paediatr J 1986;22:45-7.

35. Wechsler ME, Kelley JM, Boyd IO, et al. Active albuterol or placebo, sham acupuncture, or no intervention in asthma. N Engl J Med 2011;365:119-26.

36. Network BTSSIG. British guideline on the management of asthma. Thorax 2014;69:11-i192.

37. Poowuttikul P, Kamat D, Thomas R, Pansare M. Asthma consultations with specialists: What do the pediatricians seek? Allergy Asthma Proc 2011;32:307-12.

38. Zealand TPSoN. Best practice evidence based guideline: Wheeze and chest infection in infants less than one year. $<$ www.paediatrics.org.nz2005:53> (Accessed April 2005).

39. National Asthma E, Prevention P. Expert Panel Report 3: Guidelines for the Diagnosis and Management of Asthma. Bethesda: National Institutes of Health; 2007.

40. Australia NAC. New National Asthma Management guidelines released. National Asthma Council Autralia; 2014. <www. nationalasthma.org.au/handbook> (Accessed April 2014).

41. Rosenfeld M, Allen J, Arets BH, et al. An official American Thoracic Society workshop report: Optimal lung function tests for monitoring cystic fibrosis, bronchopulmonary dysplasia, and recurrent wheezing in children less than 6 years of age. Ann Am Thorac Soc 2013;10:S1-S11.

42. Beydon N, Davis SD, Lombardi E, et al. An official American Thoracic Society/European Respiratory Society statement: Pulmonary function testing in preschool children. Am J Respir Crit Care Med 2007;175:1304-45.

43. Gaffin JM, Shotola NL, Martin TR, Phipatanakul W. Clinically useful spirometry in preschool-aged children: Evaluation of the 2007 American Thoracic Society Guidelines. J Asthma 2010;47:762-7.

44. Sonnappa S, Bastardo CM, Wade A, et al. Symptom-pattern phenotype and pulmonary function in preschool wheezers. J Allergy Clin Immunol 2010;126:519-26.

45. Robinson M, Smart J. Allergy testing and referral in children. Aust Fam Physician 2008;37:210-3.

46. Szefler SJ, Baker JW, Uryniak T, Goldman M, Silkoff PE. Comparative study of budesonide inhalation suspension and montelukast in young children with mild persistent asthma. J Allergy Clin Immunol 2007;120:1043-50.

47. Bisgaard H, Hermansen MN, Loland L, Halkjaer LB, Buchvald F. Intermittent inhaled corticosteroids in infants with episodic wheezing. N Engl J Med 2006;354:1998-2005.

48. Nwokoro C, Pandya H, Turner S, et al. Intermittent montelukast in children aged 10 months to 5 years with wheeze (WAIT trial): A multicentre, randomised, placebo-controlled trial. Lancet Respir Med 2014;2:796-803.

49. Ducharme FM, Lemire C, Noya FJ, et al. Preemptive use of highdose fluticasone for virus-induced wheezing in young children. N Engl J Med 2009;360:339-53. 


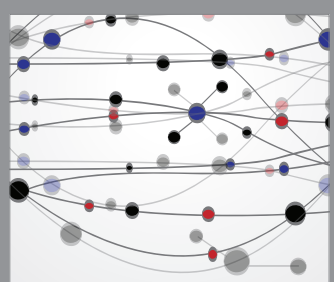

The Scientific World Journal
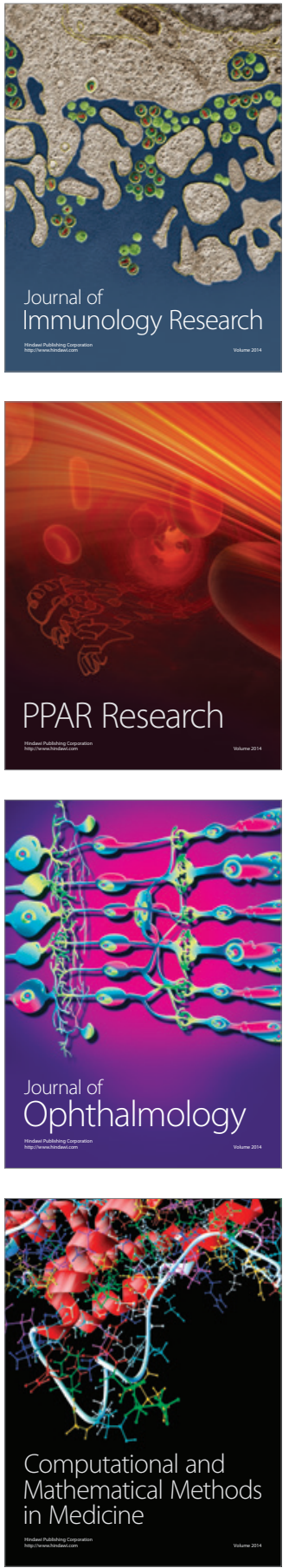

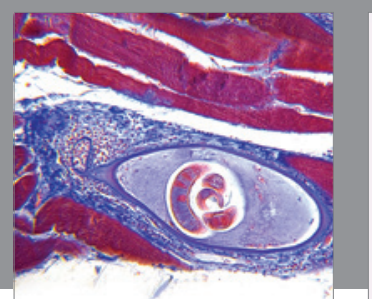

Gastroenterology Research and Practice

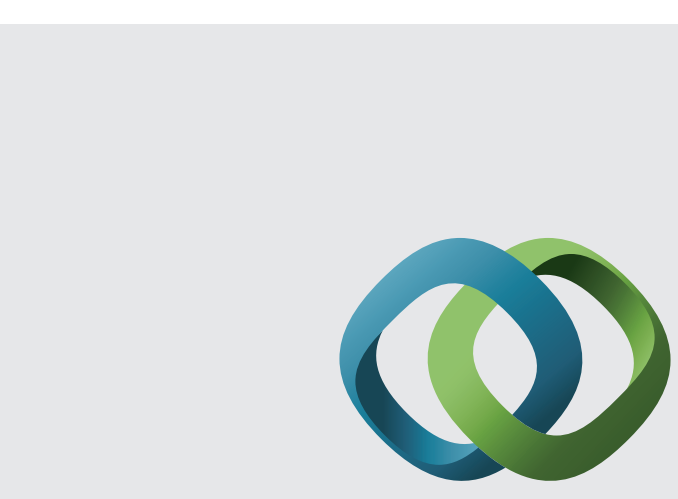

\section{Hindawi}

Submit your manuscripts at

http://www.hindawi.com
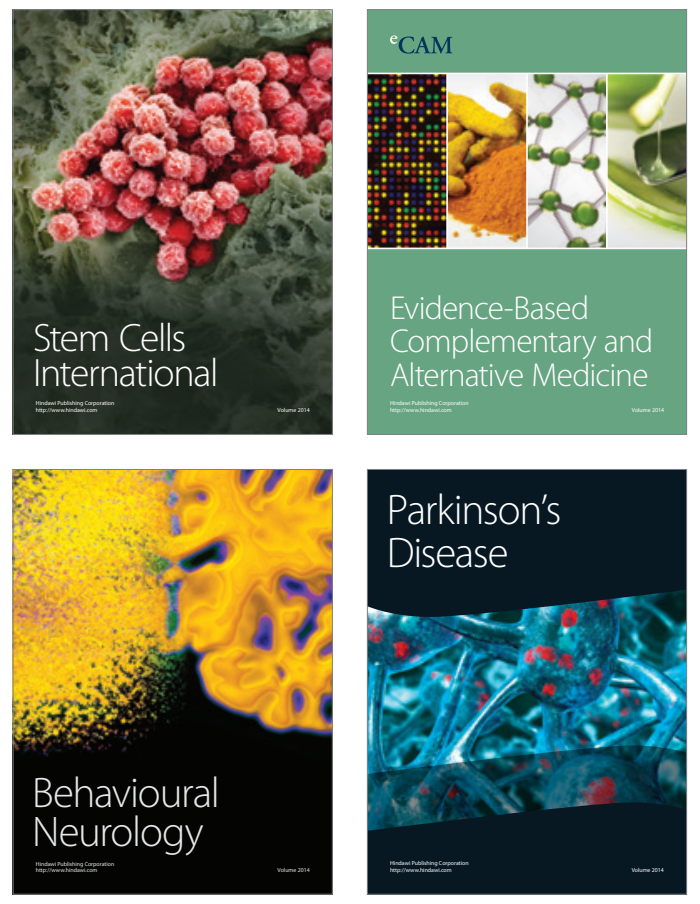
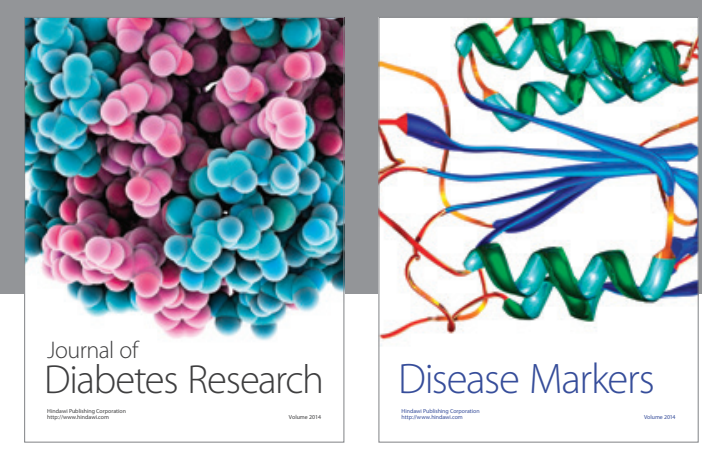

Disease Markers
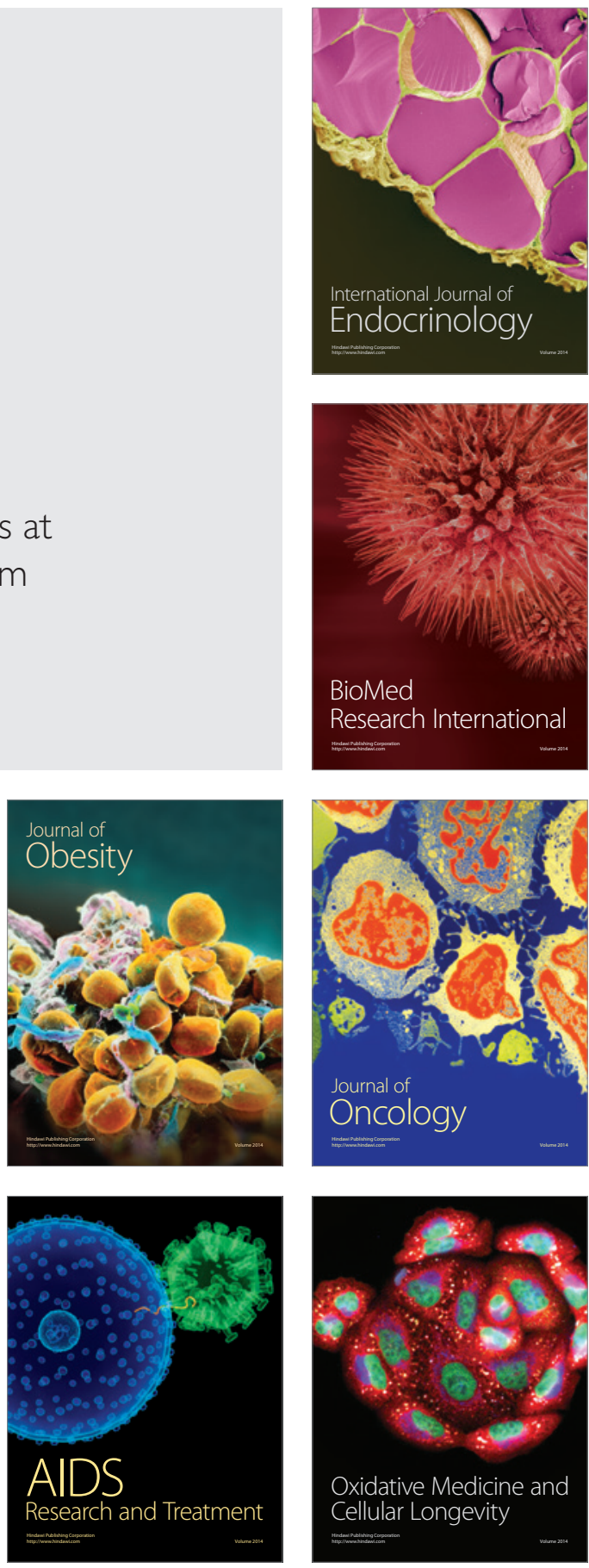